\title{
European Society of Thoracic Surgeons preoperative mediastinal staging guidelines: From face validity to external validity
}

\author{
Alessandro Brunelli, MD \\ From the Department of Thoracic Surgery, St James's University Hospital, Leeds, United Kingdom. \\ Disclosures: Author has nothing to disclose with regard to commercial support. \\ Received for publication Sept 25, 2017; accepted for publication Sept 25, 2017; available ahead of print Oct 25, \\ 2017. \\ Address for reprints: Alessandro Brunelli, MD, Department of Thoracic Surgery, St James's University Hospital, \\ Leeds LS9 7TF, United Kingdom (E-mail: brunellialex@gmail.com). \\ J Thorac Cardiovasc Surg 2018;155:796-7 \\ 0022-5223/\$36.00 \\ Copyright (C) 2017 by The American Association for Thoracic Surgery \\ https://doi.org/10.1016/j.jtcvs.2017.09.115
}

Guidelines or recommendations from a panel of experts are based on the best scientific evidence available at the time of writing. They need validation in the field. The article by Turna and colleagues ${ }^{1}$ represents an example of practical and local application of the European Society of Thoracic Surgeons (ESTS) preoperative mediastinal staging guidelines published in $2014 .^{2}$

The main objective was to verify the diagnostic accuracy of 2 critical steps in the algorithm: (1) not having any mediastinal staging in case of smaller than $3-\mathrm{cm}$ peripheral tumors without increased positron emission tomography (PET) avidity and (2) invasive mediastinal staging in all other cases with or without increased PET avidity.

The relative strength and weakness of this study include the use of an aggressive approach to stage the mediastinum when indicated, namely, video-assisted mediastinoscopy (VAM) or video-assisted mediastinoscopic lymphadenectomy (VAMLA). This represents a strength because it ensures a complete and extensive mediastinal staging (a mean of 31 lymph nodes per biopsy specimen was reported), which can reliably be interpreted to guide further treatment. It may be a weakness because endobronchial ultrasound, which now represents a commonly used staging procedure by many tumor boards, was minimally used in this study. By using this approach, the authors ${ }^{1}$ were able to find that the ESTS guidelines had an accuracy of $97 \%$ in their set of patients.

One of the most important findings of this study was that $98 \%$ of patients with peripheral, PET N0, T1 tumors were confirmed pathologically N0 after invasive staging and surgery. This finding confirmed the ESTS guidelines' recommendation that these patients do not need invasive mediastinal staging before surgery.

Another interesting finding was that of 194 tumors centrally located or larger than $3 \mathrm{~cm}$ without nodal activity at PET (cN0), 33 were found to be node positive after invasive

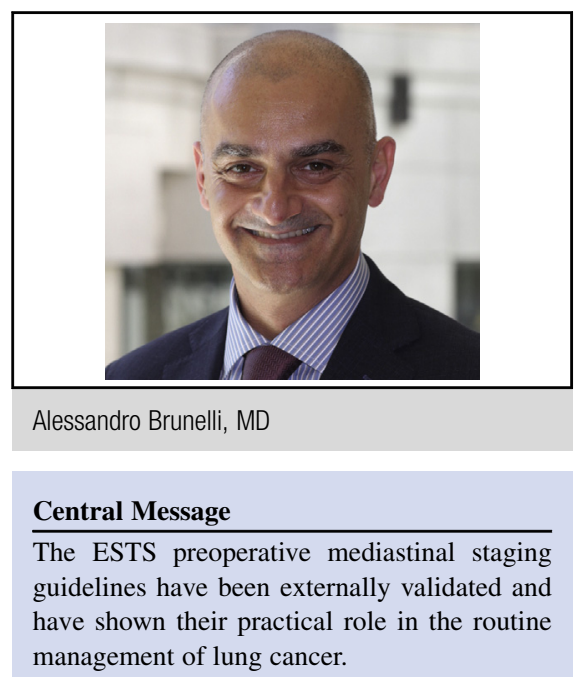

See Article page 789.

mediastinal staging (17\%). Unfortunately, there were no details provided in the study about how many patients had single or multiple station N2 disease after VAM or VAMLA. This information is relevant because patients with singlestation N2 disease may be considered for surgery up-front without invasive mediastinal staging as advocated by some authors. ${ }^{3,4}$ In other words, it would have been important to know how many patients in this group had 1 or more nodal stations involved.

Finally, the results of this study confirmed that patients with PET-positive hilar or mediastinal nodes need to undergo invasive mediastinal staging because $43 \%$ and $75 \%$ of them were found to have positive mediastinal nodes after VAM and VAMLA, respectively.

The performance of invasive mediastinal staging in clinically N2-staged patients is one of the process measures incorporated in the Composite Performance Score used to assess eligibility for European Institutional Accreditation from the ESTS database. ${ }^{5}$ Turna and colleagues ${ }^{1}$ must be commended for validating this practice with their wellconducted investigation.

\section{References}

1. Turna A, Melek H, Kara VH, Kiliç B, Erşen E, Kaynak K. Validity of the updated European Society of Thoracic Surgeons staging guideline in lung cancer patients. J Thorac Cardiovasc Surg. 2018;155:789-95. 
2. De Leyn P, Dooms C, Kuzdzal J, Lardinois D, Passlick B, Rami-Porta R, et al. Revised ESTS guidelines for preoperative mediastinal lymph node staging for non-small-cell lung cancer. Eur J Cardiothorac Surg. 2014;45: 787-98.

3. Rocco G, Nason K, Brunelli A, Varela G, Waddell T, Jones DR. Management of stage IIIA(N2) non-small cell lung cancer: a transatlantic perspective. Ann Thorac Surg. 2016;101:1247-50.
4. Lim E, McElnay PJ, Rocco G, Brunelli A, Massard G, Toker A, et al. Invasive mediastinal staging is irrelevant for PET/CT positive N2 lung cancer if the primary tumour and ipsilateral lymph nodes are resectable. Lancet Respir Med. 2015;3:e32-3. 5. Brunelli A, Berrisford RG, Rocco G, Varela G, European Society of Thoracic Sur geons Database Committee. The European Thoracic Database project: composite performance score to measure quality of care after major lung resection. Eur $J$ Cardiothorac Surg. 2009;35:769-74. 